\title{
Clinical significance of cancer stem cell markers in lung carcinoma
}

\author{
Liang Zhang ${ }^{1 \#, ~ L i a n g l a n ~ S h e n ~}{ }^{2 \#}$ and Dijun Wu ${ }^{3 凶}$ \\ 1Department of Oncology, The Second Affiliated Hospital of Nantong University, Nantong 226001, Jiangsu, PR China; 2Department of Nephrol- \\ ogy, The Second Affiliated Hospital of Nantong University, Nantong 226001, Jiangsu, PR China; ${ }^{3}$ Department of Radiotherapy, The Second Affili- \\ ated Hospital of Nantong University, Nantong 226001, Jiangsu, PR China
}

The identification of side population (SP) cells in several cancer studies has been proved to be involved in the treatment failure (chemotherapy) and tumor relapse. Here we have sorted $7 \%$ of side population (SP) cells from lung adenocarcinoma by Hoechst 33342 dye expulsion method. Further, the characterization of sorted SP cells showed cancer stem like properties such as transcriptional upregulation of stemness genes (OCT-4, SOX2 and NANOG), ATP binding cassette (ABC) transporter protein $(A B C G 2)$ and enhanced level of stem cell surface markers such as CD133 and CD44. Therefore, the aforesaid properties of lung adenocarcinoma SP cells play a significant and functional role in tumor invasion, metastasis, chemotherapeutic drug resistance and tumor recurrence in lung cancer.

Keywords: $A B C$ transporters, cancer stem cells, drug resistance, selfrenewal, tumor recurrence.

Received: 23 September, 2020; revised: 06 October, 2020; accepted: 09 December, 2020; available on-line: 20 April, 2021

छe-mail: ntWdj@qq.com

"Authors contributed equally

Acknowledgements of Financial Support: We are thankful for the funding support: this study was supported by Science and Technology Program of Nantong (No.MS12017017-3).

Abbreviations: $A B C$, TP binding cassette; $A C$, adenocarcinoma; CSCs, cancer stem cells; SP, side population

\section{INTRODUCTION}

Cells that are present in small groups within a tumor bulk and have the ability to initiate cancer growth and metastasis (Clarke et al., 2006; Visvader et al., 2008; Rosen et al., 2009;) are known as cancer stem cells (CSCs). Studies in several tumors visualized the properties of CSCs, namely overexpression of cell surface proteins, ability to differentiate into different cell types, transcriptional upregulation of stemness genes and increased cell proliferate rate (Zhou et al., 2001; Haraguchi et al., 2006; Wu et al., 2008; Schoenhals et al., 2009).

Further, the CSCs are capable of pumping out the several chemotherapeutic drugs or DNA targeting drugs and become resistant as they express various membrane spanning ATP binding cassette proteins (ABC) such as ABCB1, ABCG1 and BCRP1. CSCs can be sorted either by CD133 overexpression or FACs based Hoechst 33342 dye efflux with lower intensity of fluorescence signal (Goodell et al., 1996; Kondo et al., 2004; Hirschmann et al., 2004; Patrawala et al., 2005). These small groups of cells, which can efficiently pump the dye out of the cell owing to the overexpression of $\mathrm{ABC}$ transporter proteins, are designated as Side Population (SP) cells
(Goodell et al., 1996; Ho et al., 2007; Seo et al., 2007; Das et al., 2008; Salcido et al., 2010). The cancer stem cells-like properties of SP cells might play a major role in chemotherapy failure and tumor recurrence (Gao et al., 1998; Wang et al., 2007; Bourguignon et al., 2008). However, the precise signaling pathways and molecular mechanisms behind the side population cells mediated tumorigenesis are still unknown.

Worldwide, lung adenocarcinoma is one of the leading cause for cancer related deaths in all genders. Upon diagnosis, the average life span of lung cancer patients is about 5 years (Parkin et al., 2005). Different studies in lung cancer described that the occurrence of CSCs is responsible for inhibiting the uptake of different therapeutic drugs which leads cancer cells to resist apoptosis (Singh et al., 2004; Seo et al., 2007; Salnikov et al., 2010; Singh et al., 2010; Yue et al., 2014). As like in other solid tumors, 'lung CSCs' are also highly clonogenic, capable of self-renewal, and mutlidrug apoptosis-resistant (Salnikov et al., 2010; Singh et al., 2010). Accordingly, the sorting and further functional characterization of lung cancer SP cells (Das et al., 2008) will definitely pave the way for developing novel anti-cancer drugs that could effectively target CSCs. Therefore, we have performed functional characterization of lung adenocarcinoma SP cells.

\section{MATERIALS AND METHODS}

\section{Cancer samples and culture}

All the procedures (sample collection and surgery) were followed according to the ethical rules approved by The Second Affiliated Hospital of Nantong University (License number: SEC013244). The cancer samples were obtained in agreement with patients oral consent. According to The Second Affiliated Hospital of Nantong University rules and regulations, we do not provide any data for the identification of patients in this manuscript.

Lung carcinoma samples were obtained during surgery. Sample details: $\mathrm{n}=15$ (Male-8; female-7), region - adenocarcinoma (AC), stage: p'T1pN2pMX(IIIA) and pT3pN2pMX(IIIA). The obtained tumor samples were washed several times and subjected to overnight incubation in DMEM-F12 medium with antibiotics such as penicillin and streptomycin. Tissues were enzymatically digested by using collagenase II $(20 \mathrm{mg} / \mathrm{mL})$ for 2 hours at $37^{\circ} \mathrm{C}$. Recovered cells were cultured in $\mathrm{T} 75$ flask in DMEM-F12 medium (Gibco-Invitrogen) supplemented with 10\% FBS and antibiotics (penicillin and streptomycin). Cells were incubated in $5 \% \mathrm{CO}_{2}$ at $37^{\circ} \mathrm{C}$. Once 
the cells became confluent, they were washed and transferred to the flask containing fresh medium.

\section{Hoechst 33342 dye labeling}

Study groups were assigned as Control: cells labelled with Hoechst dye alone $(n=7)$ and Verapamil treatment $(\mathrm{n}=7)$ : cells labelled with Hoechst dye and $75 \mu \mathrm{M}$ of Verapamil drug as well. The propidium iodide staining and labelling of Hoechst 33342 dye are followed exactly as per (Liu et al., 2015). The method of sorting of side population cells by flow cytometry method was exactly followed by the procedure as described previously (Hirschmann et al., 2004; Liu et al., 2015).

\section{Biochemistry}

Cell lysates extraction, protein preparation and separation by SDS-PAGE were performed as described previously (Yue et al., 2014). Primary rabbit antibodies (rabbit anti-human ABCG2, CD133 and CD44) and secondary antibody anti-rabbit-IgG HRP conjugated (Santa Cruz) were used. Protein signals were detected by ECL kit with Biorad densitometer.

\section{Real-time PCR}

Using Reverse Transcriptase kit (Fermentas), the total RNA was extracted, complementary DNA was synthesized and subsequently RT-qPCR was performed in iCycler (Biorad). The sequences of the primers and the signal quantification were performed as described previously (Yue et al., 2014). The PCR parameters applied for this study were as follows: initial denaturation, $93^{\circ} \mathrm{C}$ for $40 \mathrm{sec}$; followed by 40 cycles of denaturation, $93^{\circ} \mathrm{C}$ for 5 min.; annealing, $58^{\circ} \mathrm{C}$ for $45 \mathrm{sec}$, and extension, $72^{\circ} \mathrm{C}$ for $30 \mathrm{~s}$. Final extension was executed at $72^{\circ} \mathrm{C}$ for $10 \mathrm{~min}$. The amplified PCR products were electrophoresed on $1.2 \%$ agarose gel and stained with ethidium bromide. The band intensity was measured using Image J software and the relative RNA expression level was adjusted with GAPDH level, which was used as housekeeping gene.

\section{In vitro assays}

Matrigel invasion assay. D six-well matrigel invasion chambers (BD Biosciences) were applied for this assay. $10^{4}$ cells were plated per insert in serum free medium while the insert outlets contained DMEMF12 supplemented with 10\% FBS as chemoattractant. Cells were grown for 48 hours and further subjected to washing and wiping the top layer of Matrigel with cotton swabs. The membrane containing invading cells was stained with hematoxylin for 5 minutes and then visualized under a light microscope using a $60 \times$ objective for counting the number of cells invaded. The quantitative graph represents the average values from three independent experiments.

Cell proliferation assay. This experiment was performed in triplicate. Both SP and non-SP cells were seeded in a 96-well plate at a density of $2 \times 10^{6}$ cells/ well. The optical density (OD) at $450 \mathrm{~nm}$ was measured to determine cell proliferation activity. This measurement was taken for 7 days continuously and the growth graph presented the average value of three different experiments. Differentiation and Matrigel assays protocols were followed as per (Ho et al., 2007). Similarly, the sphere formation assay was carried out exactly by the protocol descried in the literature (Yanamoto et al., 2011).
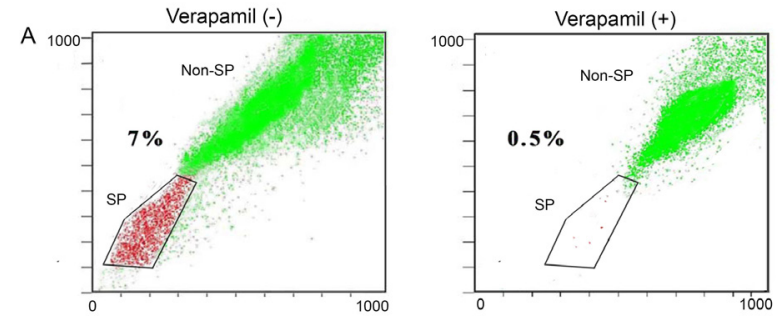

B

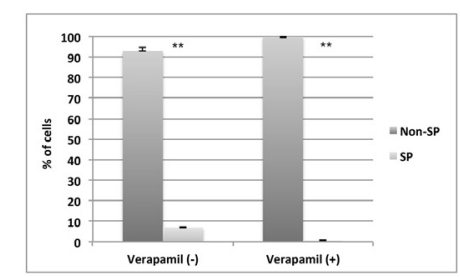

Figure 1. Side population cells in metastatic lung adenocarcinoma.

(A) Representative flow cytometry graph of dot plot analysis demonstrating the existence of SP cells which efflux Hoechst 33342 dye in the gated region. (B) Quantitative graph of dot plot analysis from the FACs profile. Error bar - standard deviation; $\left({ }^{* *} P<0.01\right)$.

\section{Statistical analysis}

Student's $t$-test was performed for comparing the significance of differences between two different groups and the values denoted in the quantification charts are mean \pm S.D. The values $* P<0.05$ and $* * P<0.01$ are considered as significant.

\section{RESULTS}

\section{Isolation of side population cells from lung adenocarcinoma}

By Hoechst dye exclusion assay we have found that side population cells accounted for $7 \%$ (Fig. 1A) of lung adenocarcinoma samples and that their rate was significantly diminished to $0.5 \%$ by subsequent treatment of verapamil, which inhibits the function of $\mathrm{ABC}$ transporters (Fig. 1B). Hence, this result confirms the presence of $\mathrm{ABC}$ transporter proteins and its exclusive function of drug expulsion of SP cells.

\section{Expression profile of SP and non-SP cells from lung adenocarcinoma}

Expression profile of stemness and ABC transporter genes were analyzed by RT-qPCR. The transcriptional regulation of stemness and $\mathrm{ABC}$ transporter genes such as OCT-4, NANOG, SOX2 and ABCG2 were found to be significantly accelerated in SP cells (Fig. 2A). Subsequently, we have performed western blot analysis to monitor the expression pattern of cell surface proteins (CD133 and CD44) and ABCG2 as well. Interestingly, SP cells overexpressed CD133, CD44 and ABCG2 while the parental population cells did not (Fig. 2B). In addition, we observed that the number of total spheres formed by SP cells increased much faster and reached higher values than that formed by non-SP cells (Fig. 3A). The SP cells grew faster, formed tumor spheres more rapidly and more efficiently - spheres produced by SP cells were all augmented in size compared to non-SP cells (Fig. 3B). Therefore, the SP cells can be regarded as able to self- 
A
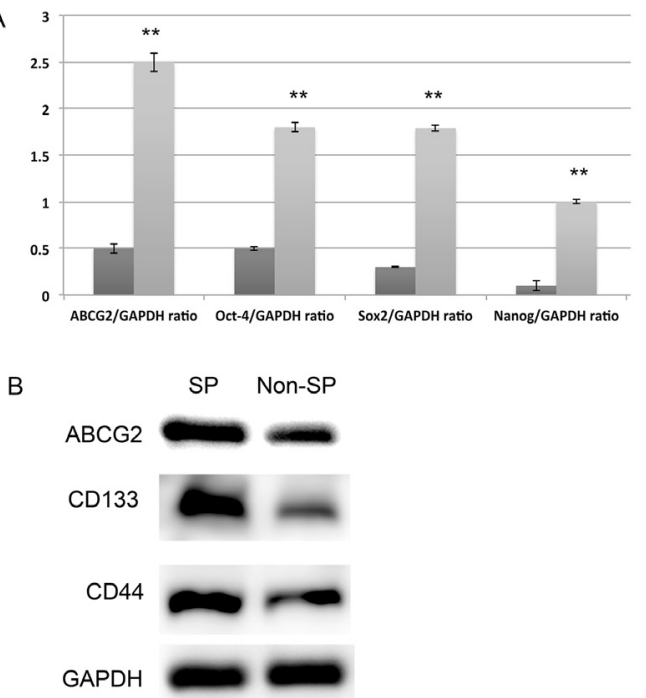

Figure 2. Expression profile of lung adenocarcinoma SP cells. The RT-PCR evaluation (A) and western blots (B) showing the transcriptional upregulation of genes and expression pattern of surface proteins in SP cells, respectively. For both the analysis, the house keeping gene/protein used here is GAPDH. Error bar standard deviation; $\left.{ }^{* *} P<0.01\right)$

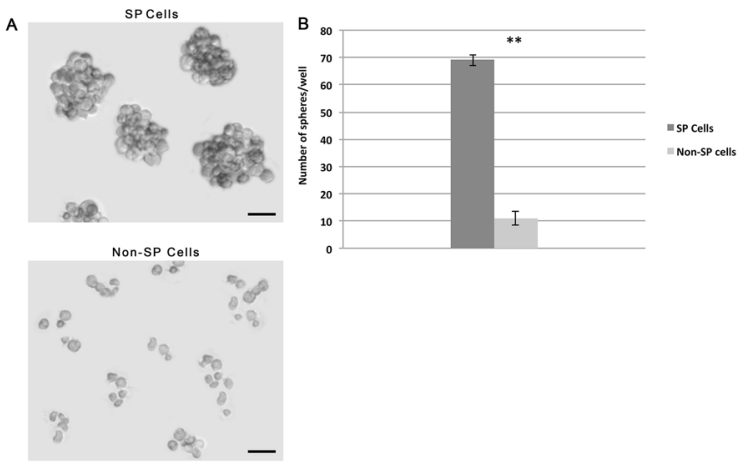

Figure 3. Efficiency of sphere formation in SP cells.

(A) Bright field microscopic pictures showing the size and morphology of the spheres generated by SP and parental non-SP cells. (B) Comparison of quantity of spheres formed by two different population of cells. Error bar - standard deviation; ${ }^{* *} P<0.01$.

renew, highly tumorigenic, as well as crucial for tumor recurrence and metastasis.

\section{SP cells are highly proliferative and resist DNA targeting drugs}

To evaluate the in vivo tumorigenesis potential, we have performed in vitro cell proliferation assay for lung adenocarcinoma SP cells. The FACs sorted SP cells were proliferating much faster on the third day itself (D3) and reached $90 \%$ confluence on the seventh day. The growing rate and confluence abilities of non-SP cells were significantly lower than that of SP cells (Fig. 4A). Similarly, the cell differentiation assays revealed that the morphology of SP cells was remarkably changed. SP cells lost their original identity and were extended to form filamentous structures similar to ones present in fibroblasts (Fig. 4B). In addition, the SP cells became resistant to anti-cancer drugs and had prolonged cell survival rate once treated with drugs such as Paclitaxel, Etoposide,

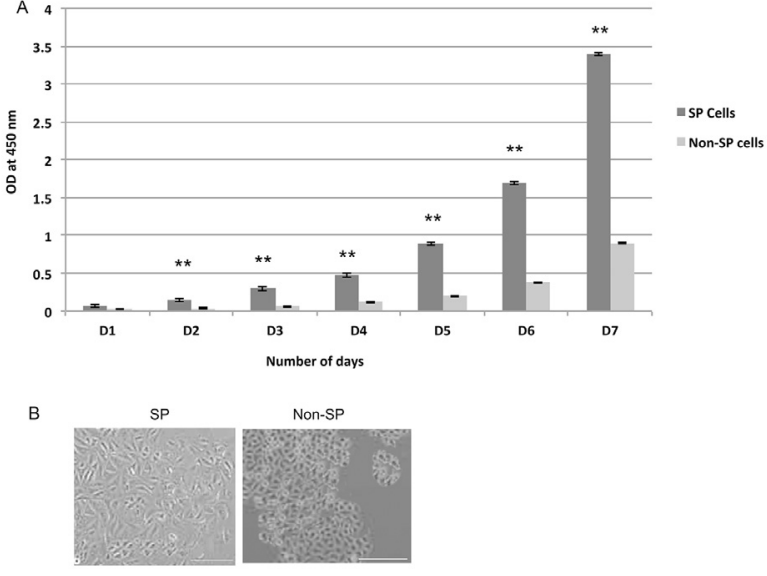

Figure 4. Cell proliferation and differentiation capacity of SP cells.

(A) Measurement of cell growth rate at optical density (OD) $450 \mathrm{~nm}$. (B) The FACs sorted SP cells underwent morphological changes and long filaments like in fibroblasts were formed. Error bar standard deviation; ${ }^{* *} P<0.01$.

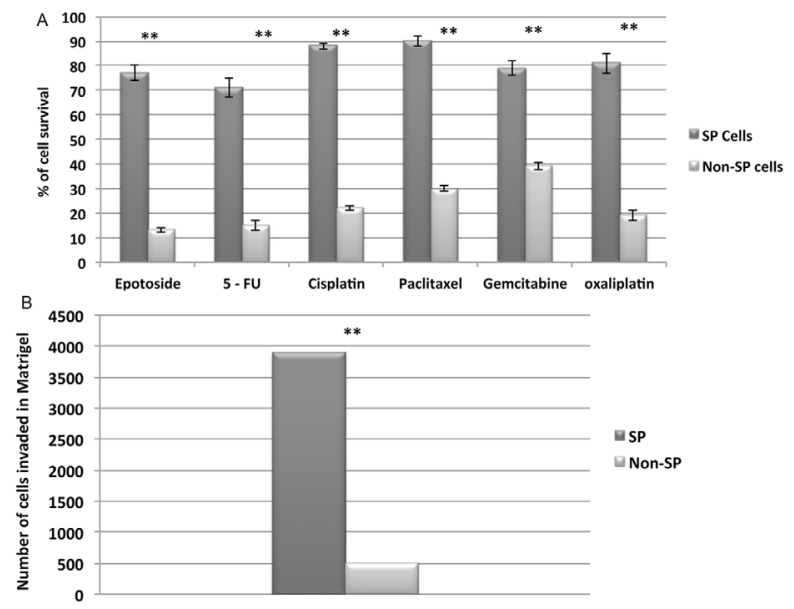

Figure 5. Chemoresistance and high invasion of SP cells.

(A) Quantification graph showing the cell survival rate of SP cells and parental non-SP cells after the DNA targeting drugs treatment. (B) Matrigel quantification showing the rate of invasiveness between SP and non-SP cells. Error bar - standard deviation; $\left({ }^{* *} P<0.01\right)$.

Cisplatin, Gemcitabine, Oxaliplatin and 5-Flurouracil (5FU) (Fig. 5A). The number of SP cells able to invade through the matrigel was significantly higher when compared to non-SP cells (Fig. 5B). The matrigel invasion assay data suggest SP cells do have higher invasion potential. Hence, all our findings suggest that lung adenocarcinoma SP cells play an essential role in the resistance to chemotherapeutic targets that might be involved in treatment failure, recurrence of tumor and invasion.

\section{DISCUSSION}

In the present study, we have identified a small, rare group of cancer initiating cells from lung adenocarcinoma samples called "side population (SP)" cells from lung adenocarcinoma samples, which showed the properties of CSCs. In line with previous findings (Ho et al., 2007; Nakatsugawa et al., 2011), our results also demonstrated the properties of SP cells which facilitate the en- 
hanced cell proliferation rate, self-renewal capacity and metastasis of lung adenocarcinoma. We have found that approximately $7 \%$ of the cells from the tumor of lung adenocarcinoma samples were SP cells, which efflux the Hoechst 33342 dye by the over expression of ABCG2 pumps. Once treated with verapamil (ABCG2 inhibitor), the drug efflux activity was compromised and therefore the proportion of SP decreased to $0.5 \%$. High expression profile of ABCG2 in SP cells contributes to severe resistance to several anti-cancer drugs and promotes prolonged cell survival as well. Therefore, these results confirm the presence and active role of ABC transporter protein in drug resistance of cancer stem cells which leads to the attenuation of apoptosis in cancer cells.

The FACs assorted SP cells were characterized phenotypically and functionally. They exhibited high cell proliferation rate and self-renewing capacity (Chiou et al., 2010; Nakatsugawa et al., 2011; Singh et al., 2012). They were highly capable of forming several-fold higher numbers of tumor spheres all of which were significantly bigger in size over the time course when compared to parental non-SP cells. The high potent sphere formation efficiency is regulated and driven by up-regulation of stemness genes such as OCT-4, SOX 2 and NANOG, and is crucial for metastasis of lung adenocarcinoma patients (Salnikov et al., 2010; Nakatsugawa et al., 2011; Singh et al., 2012; Yue et al., 2014). Similar studies in lung cancers reported that the transcriptional upregulation of embryonic stemness genes is highly tumorigenic, may lead to epithelial mesenchymal transition (EMT) like features and might also involve high differentiation properties of SP cells. The possible explanation could be that SOX2 upregulation is due to elevated EGFR signaling mechanism whereas the OCT-4 and NANOG are upregulated by different independent pathways, which remains to be elucidated (Amann et al., 2005; Gazdar et al., 2008; Salnikov et al., 2010; Singh et al., 2012). Recent reports also showed that overexpression of OCT-4 and NANOG increases the tumor initiating property of A549 cells (Chiou et al., 2010).

Further, the enhanced expression of exclusive markers for CSCs such as CD133 and CD44 in SP cells are responsible for chemo-and radiotherapy resistance (Honeth et al., 2008). These cell surface proteoglycans play a major role in cancer relapse, progression, and metastasis in several tumors (Honeth et al., 2008). Consequently, we identified that SP cells are highly invasive in matrigel assay. However, the complexity of mechanisms and receptor signaling pathways involved in SP cells function still needs to be studied in more detail. Taken together, our findings strengthen the hypothesis that elevated levels of $\mathrm{ABC}$ transporters and stemness genes promote stem like properties of SP cells which are significantly sufficient for tumor initiating, self-renewing, tumor invasion, metastasis, chemotherapy resistance and tumor recurrence. Further, more research is needed to elucidate the pathways and mechanisms involved in stemness properties and tumorigenic nature of SP cells, as this might lead to the development of a unique chemotherapeutic drug which eradicating CSCs to preclude the tumor recurrence.

\section{REFERENCES}

Amann J, Kalyankrishna S, Massion PP, Ohm JE, Girard L, Shigematsu H, Peyton M, Juroske D, Huang Y, Salmon JS, Kim YH (2005) Aberrant epidermal growth factor receptor signaling and enhanced sensitivity to EGFR inhibitors in lung cancer. Cancer Res 65: 226235. PMID: 15665299
Bourguignon LY, Peyrollier K, Xia W, Gilad E (2008) HyaluronanCD44 interaction activates stem cell marker Nanog, Stat-3-mediated MDR1 gene expression, and ankyrin-regulated multidrug efflux in breast and ovarian tumor cells. J Biol Chem 283: 17635-17651. https://doi.org/10.1074/jbc.M800109200

Chiou SH, Wang ML, Chou YT, Chen CJ, Hong CF, Hsieh WJ, Chang HT, Chen YS, Lin TW, Hsu HS, Wu CW (2010) Coexpression of Oct4 and Nanog enhances malignancy in lung adenocarcinoma by inducing cancer stem cell-like properties and epithelial-mesenchymal transdifferentiation. Cancer Res 70: 10433-10444. https://doi. org/10.1158/0008-5472.CAN-10-2638

Clarke MF, Dick JE, Dirks PB, Eaves CJ, Jamieson CH, Jones DL, Visvader J, Weissman IL, Wahl GM (2006) Cancer stem cellsperspectives on current status and future directions: AACR Workshop on cancer stem cells. Cancer Res 66: 9339-9344. https://doi. org/10.1158/0008-5472.CAN-06-3126

Das B, Tsuchida R, Malkin D, Koren G, Baruchel S, Yeger H (2008) Hypoxia enhances tumor stemness by increasing the invasive and tumorigenic side population fraction. Stem Cells 26: 1818-1830. https://doi.org/10.1634/stemcells.2007-0724

Gao AC, Lou W, Sleeman JP, Isaacs JT (1998) Metastasis suppression by the standard CD44 isoform does not require the binding of prostate cancer cells to hyaluronate. Cancer Res 58: 2350-2352

Gazdar AF, Minna JD (2008) Deregulated EGFR signaling during lung cancer progression: mutations, amplicons, and autocrine loops. Cancer Prev Res 1: 156-160. https://doi.org/10.1158/1940-6207.CAPR08-0080

Goodell MA, Brose K, Paradis G, Conner AS, Mulligan RC (1996) Isolation and functional properties of murine hematopoietic stem cells that are replicating in vivo. J Exp Med 183: 1797-806. https:// doi.org/10.1084/jem.183.4.1797

Haraguchi N, Utsunomiva T, Inoue H, Tanaka F, Mimori K, Barnard GF, Mori M (2006) Characterization of a side population of cancer cells from human gastrointestinal system. Stem Cells 24: 506-513. https://doi.org/10.1634/stemcells.2005-0282

Hirschmann-Jax C, Foster AE, Wulf GG, Nuchtern JG, Jax TW, Gobel U, Goodell MA, Brenner MK (2004) A distinct "side population" of cells with high drug efflux capacity in human tumor cells. Proc Natl Acad Sci U S A 101: 14228-14233. https://doi.org/10.1073/ pnas.0400067101

Ho MM, Ng AV, Lam S, Hung JY (2007) Side population in human lung cancer cell lines and tumors is enriched with stem-like cancer cells. Cancer Res 67: 4827-4833. https://doi.org/10.1158/0008-5472. CAN-06-3557

Honeth G, Bendahl PO, Ringnér M, Saal LH, Gruvberger-Saal SK, Lövgren K, Grabau D, Fernö M, Borg A, Hegardt C (2008) The CD44p/CD24 pheno- type is enriched in basal-like breast tumors. Breast Cancer Res 10: 53. https://doi.org/10.1186/bcr2108

Kondo T, Setoguchi T, Taga T (2004) Persistence of a small subpopulation of cancer stem-like cells in the C6 glioma cell line. Proc Natl Acad Sci U S A 101: 781-786. https://doi.org/10.1073/ pnas.0307618100

Liu Y, Cui P, Chen J, Li W (2015) Isolation and phenotypic characterization of side population cells in oral squamous cell carcinoma. Mol Med Rep 5: 3642-3646. https://doi.org/10.3892/mmr.2014.3133

Nakatsugawa M, Takahashi A, Hirohashi Y, Torigoe T, Inoda S, Murase $\mathrm{M}$, Asanuma $\mathrm{H}$, Tamura $\mathrm{Y}$, Morita $\mathrm{R}$, Michifuri $\mathrm{Y}$, Kondo $\mathrm{T}$ (2011) SOX2 is overexpressed in stem-like cells of human lung adenocarcinoma and augments the tumorigenicity. Lab Invest 91: 17961804. https://doi.org/10.1038/labinvest.2011.140

Parkin DM, Bray F, Ferlay J, Pisani P (2005) Global cancer statistics, 2002. CA Cancer J Clin 55: 74-108. https://doi.org/10.3322/canjclin. 55.2.74

Patrawala L, Calhoun T, Schneider-Broussard R, Zhou J, Claypool K, Tang DG (2005) Side population is enriched in tumorigenic, stemlike cancer cells, whereas ABCG2+ and ABCG2- cancer cells are similarly tumorigenic. Cancer Res 65: 6207-6219. https://doi. org/10.1158/0008-5472.CAN-05-0592

Rosen JM, Jordan CT (2009) The increasing complexity of the cancer stem cell paradigm. Science 324: 1670-1613. https://doi. org/10.1126/science.1171837

Salcido CD, Larochelle A, Taylor BJ, Dunbar CE, Varticovski L (2010) Molecular characterisation of side population cells with cancer stem cell-like characteristics in small-cell lung cancer. $\mathrm{Br} J$ Cancer 102: 1636-1644. https://doi.org/10.1038/sj.bjc.6605668

Salnikov AV, Gladkich J, Moldenhauer G, Volm M, Mattern J, Herr I (2010) CD133 is indicative for a resistance phenotype but does not represent a prognostic marker for survival of non-small cell lung cancer patients. Int J Cancer 126: 950-958. https://doi.org/10.1002/ ijc. 24822

Schoenhals M, Kassambara A, De Vos J, Hose D, Moreaux J, Klein B (2009) Embryonic stem cell markers expression in cancers. Biochem Biophys Res Commun 383: 157-162. https://doi.org/10.1016/j. bbrc. 2009.02.156

Seo DC, Sung JM, Cho HJ, Yi H, Seo KH, Choi IS, Kim DK, Kim JS, Am AE, Shin HC (2007) Gene expression profiling of cancer 
stem cell in human lung adenocarcinoma A549 cells. Mol Cancer 6 : 75. https://doi.org/10.1186/1476-4598-6-75

Singh SK, Hawkins C, Clarke ID, Squire JA, Bayani J, Hide T, Henkelman RM, Cusimano MD, Dirks PB (2004) Identification of human brain tumour initiating cells. Nature 432: 396-401. https://doi. org/10.1038/nature03128

Singh A, Settleman J (2010) EMT, cancer stem cells and drug resistance: an emerging axis of evil in the war on cancer. Oncogene 29: 4741-4751. https://doi.org/10.1038/onc.2010.215

Singh S, Trevino J, Bora-Singhal N, Coppola D, Haura E, Altiok S, Chellappan SP (2012) EGFR/Src/Akt signaling modulates Sox2 expression and self-renewal of stem-like side-population cells in non-small cell lung cancer. Mol Cancer 11: 1-5. https://doi. org/10.1186/1476-4598-11-73

Visvader JE, Lindeman GJ (2008) Cancer stem cells in solid tumours: accumulating evidence and unresolved questions. Nat Rev Cancer 8: 755-768. https://doi.org/10.1038/nrc2499

Wang J, Guo LP, Chen LZ, Zeng YX, Lu SH (2007) Identification of cancer stem cell-like side population cells in human nasophar- yn- geal carcinoma cell line. Cancer Res 67: 3716-3724. https://doi. org/10.1158/0008-5472.CAN-06-4343

Wu C, Alman BA (2008) Side population cells in human cancers. Cancer Lett 268: 1-9. https://doi.org/10.1016/j.canlet.2008.03.048

Yanamoto S, Kawasaki G, Yamada S, Yoshitomi I, Kawano T, Yonezawa H, Rokutanda S, Naruse T, Umeda M (2011) Isolation and characterization of cancer stem-like side population cells in human oral cancer cells. Oral Oncol 47: 855-860. https://doi.org/10.1016/j. oraloncology.2011.06.501

Zhang Y, Quan RF, Chen WS, Ye ZM, Li WX (2014) Phenotypic characterization of drug resistance and tumor initiating cancer stem cells from human bone tumor osteosarcoma cell line OS-77. Bangladesh J Pharmacol 9: 437-42

Zhou S, Schuetz JD, Bunting KD, Colapietro AM, Sampath J, Morris JJ, Lagutina I, Grosveld GC, Osawa M, Nakauchi H, Sorrentino BP (2001) The ABC transporter Bcrp1/ABCG2 is expressed in a wide variety of stem cells and is a molecular determinant of the side-population phenotype. Nat Med 7: 1028-1034. https://doi.org/10.1038/ nm0901-1028 